\title{
SCIENCE AND LITERARY STYLE IN ROBERT BURTON'S “CENTO OUT OF DIVERS WRITERS”
}

\section{BY LEONARD GOLDSTEIN}

DR. GoldsteIn, a graduate of the University of Wisconsin who holds a doctorate from Brown University, came to Rutgers in 1955. He is a specialist in English literature of the seventeenth century.

I N 1954 the Rutgers University Library received as a gift from Mr. Ogden White, through Mr. John Fleming, a long standing friend of the Library, a first edition of Robert Burton's Anatomy of Melancholy ( $162 \mathrm{r}$ ). Handsomely bound in morocco and bordered in gold, the quarto, later enlarged by Burton into a folio, is a fine copy.

Recent criticism of the Anatomy tends to regard it as a serious work on melancholy that manifests the materialism and determinism that in part characterizes Galilean science. But that a relationship exists between the peculiarities of Burton's style and the methods of Galilean science, as Burton apprehended them, has not been suggested.

One aspect of Burton's style is particularly arresting: he will make a statement and then reinforce it by stringing out behind it synonyms or synonymous phrases that seem to exhaust the capacity of the language. Such a device is not unknown to Renaissance rhetorical practice; variations of it go under the names Synonymia, Enumeratio, or Accumulation. ${ }^{1}$ The device is employed by Burton in his citations of authorities to prove a point: he will make a statement and then support it by an accumulation of authorities who, however remotely, have something to say on the subject. Hence, the list will include negative and positive citations, with the raised contradictions left unresolved. The main character of this procedure appears to be not so much the weight of the particular authority cited, but the sheer weight of authorities. This manner of writing occurs not only

${ }^{1}$ Henry Peacham, The Garden of Eloquence (1593), a facsimile reproduction with an introduction by William G. Crane (Gainesville, Florida, 1954), pp. 125, 149; John Hoskins, Directions for Speech and Style, ed. Hoyt H. Hudson (Princeton, 1935), p. 24. 
in an occasional sentence or paragraph but in almost every sentence. Arrested by this excess, one begins to think that the style is not merely a rhetorical device pushed to an extreme, but that a different informing pressure is at work that only looks like Enmeratio.

This informing pressure, we should like to suggest, was the quantifying tendency of Galilean science that had become a part of Burton's style of thought without, however, Burton being at all aware of it. Not only did the Galilean materialism and determinism reveal themselves in Burton, ${ }^{2}$ but also its generalizing, quantifying, and secularizing sides, although these aspects are not developed to the level of Galileo or Harvey, compared with whom Burton is no scientist. What we do find in Burton are tendencies in the Galilean direction, appearances of the scientific method in distorted or undeveloped form. One such form is Enumeratio, apparently of the rhetorician's handbook. To demonstrate this connection between thought formation and literary style, it will be necessary to discuss Galilean science.

From the I 4 th to the beginning of the I $7^{\text {th }}$ century there arose those conditions that in the I 6th century brought about what we call the development of science. ${ }^{3}$ Usually neglected in the traditional history of the development of science and culture is an explanation of how a kind of mentality is produced by means of which problems are posed, solved, or satisfactorily interpreted. Our problem resolves itself into asking about origins of this type of man who had this ability. It is suggested here that the solution and its technique were preceded by the development of an attitude which made the solution and the development of technique possible. What is meant by the terms "scientific method" and "scientific attitude"? Roughly, they meant that nature could be defined and analyzed quantitatively. We have already suggested that in a peculiar way Burton exhibits this attitude. Whence does it arise?

Craft production had replaced feudal agriculture. Arising out of the need to reduce the cost of production in an emerging competitive society, the factory, first in the congregating of workers under one roof and the aligning of their work in however primitive a

\footnotetext{
${ }^{2}$ G. F. Sensabaugh, The Tragic Muse of John Ford (Stanford, 1944), Chap. 2.

${ }^{3}$ For the following analysis of the relation of science to its cultural milieu, I am largely indebted to Karl H. Niebyl, The Background of Economic Analysis (Honolulu, T.H., I945), Chap. XIV. I have also had the advantage of reading a number of Dr. Niebyl's MSS on Renaissance science.
} 
fashion; and, secondly, in the utilization in these factories of water power, bringing about an entirely new functional relation of laborproduced a significant and lasting effect on man as a social being. Now an effective wall against an all-embracing social consciousness was introduced between the individual and society in the form of limited yet complete experience in the manufacturing establishment in terms of which the individual became separated from the larger societal experience. The individuality of the artisan gave way to the average energy of the wage worker. It is here, in the expanding reality of factory production, that those conditions emerged that in the experience of men were average and quantifiable, and in which he, as the producing energy, became quantifiable. To solve the general problem of cheapening the cost of production in a type of productive process that no longer involved individual artisans in craft production but "the behavior of a unit of production representing an integrated division of labor around a central power, the problem had to be dealt with abstractly and as a whole consisting of interdependent parts, for we have . . . as a subject matter which in a sense for the first defied a pragmatic attitude toward it as one can't 'touch' the interdependence of a coordinated group of workers." tifying and abstracting $W$ eltbild emerged not so much as a variation from a previous philosophic system, but out of the way men experienced life. It was the intellectuals, men like Galileo, who, as part of the new way of life, though not directly engaged in economic production, first expressed the new way of life in comprehensive theoretical form.

In Galilean thinking ${ }^{5}$ the generalizations are in the order of departing from the particular into an abstract mechanistic system within which and from which the particular derives its meaning. The Galilean world is an abstract Euclidean universe of frictionless perfect spheres and inclined planes the operations of which are expressible in precise numerical terms since its uniformly structured

4 Niebyl, pp. 282-83. See also Karl Mannheim, "Conservative Thought" in Essays on Sociology and Social Psychology, ed. Paul Kecskemeti (New York, 1953), pp. 86-87.

${ }^{5}$ See Kurt Lewin, "The Conflict between Aristotelian and Galilean Modes of Thought in Contemporary Psychology," in A Dynamic Theory of Personality, trans. Donald K. Adams and Karl E. Zener (New York, 1935), Chap. I; Ernst Cassirer, The Philosophy of the Enlightenment, trans. Fritz Z. Koeln and James C. Pettigrove (New York, 1955), Pp. 237-8; A. R. Hall, The Scientific Revolution ${ }_{1500-1800}$ (Boston, I 956), pp. I68-1 72. 
and unchanging elements behave regularly in a ubiquitous gravitational field.

In Aristotle the phenomenon is conceived as a particle of a larger whole, all attributes being derived from the whole. Individualities including abnormalities and diseases are considered products of the forces emanating from the whole and manifesting themselves in their various forms in balance or imbalance in the individual. The quantifying atomism of the $I 6$ th and $I$ th centuries is fundamentally different. Here the point of departure is the discrete particle; the observed particle and its laws of behavior are arrived at in the form of generalizations. The Galilean and Aristotelian interpretations of man and the world are opposite. Both approaches deal in abstractions, both include observations; yet, in Aristotle the observations are $e x$ post and the generalizations are a priori; in Galileo observations are primary and generalizations are derived from them.

When we turn from the work of Galileo or Harvey to that of Burton, we are struck by palpable differences. In both Galileo and Harvey not only is the abstract, quantitative method well developed and producing empirically verifiable results, but there is also a high degree of awareness of the new scientific method being employed. In Burton, on the other hand, there is no consciousness of theory, no consciously applied mathematical schemata to accumulated empirical data, and no experimental procedure. Where he refers to method, he thinks in terms of formal logic, not of the lawfulness of the physical universe. ${ }^{6}$

From such a comparison between Galileo or Harvey and Burton, it would appear that the latter emerges as an Aristotelian pur sang. And such a judgment would appear to be confirmed by a perusal of Burton's section on anatomy (I, I68-92), which reveals all too clearly the Aristotelian classificatory system of medieval science. But it would be erroneous to conclude from such a comparison that with regard to science Burton was wholly traditionalistic. In Galileo we have the appearance of the fully integrated scientist. But if we concentrate attention only on men such as Galileo, we shall be unable to explain how the scientific attitude spread to become the characteristic $W$ eltanschaung of our time, for the scientific attitude could not spread unless it was already latent in the culture. The spread of

${ }^{6}$ The Anatomy of Melancholy, ed. A. R. Shilleto (London, 1926), 1, 86. 
this new attitude would not appear everywhere within a country at the same time, or with the high degree of development we find, say, in Harvey. In other words, it is intellectuals like Galileo who raise to the level of highest development what is latent in a given stage of culture, and from them the theories spread through the culture to become recognized a posteriori as the characteristic style of thought for that culture. Today the least educated person appeals to a completely secularized abstract reason as the final arbiter in any dispute: seven hundred years ago this was not the case.

The uneven spread of the scientific attitude may be illustrated by observing that even men like Copernicus retained valuative and vitalistic conceptions foreign to Galilean science, while Bruno "repudiates every attempt at a quantitative interpretation of natural phenomena." The new way of thinking varies all the way from the fully conceptualized Weltbild of Galileo to that of the man in the street whose awareness of a new way of thinking is only being differentiated from an intuitive "merely endured psychical state" as a "non-theoretical but meaningful pattern of experience."

Between these polar opposites stands an average intellectual like Burton in whom the new science shows itself in the form of tendencies toward full integration that are imbedded in a matrix of pretheoretical intuitions and pre-scientific conceptions. For example, no sooner has Burton begun his enumeration of the causes of melancholy than he goes off on a tangent with "A Digression of the nature of Spirits, bad Angels or Devils, and how they cause Melancholy," citing authorities as he goes:

... although the question be very obscure, according to Postellus, full of controversy and ambiguity, beyond the reach of human capacity, fateor excedere vires intentionis meae, saith Austin, I confess I am not able to understand it, finitum de infinito non potest statuere, we can sooner determine with Tully, de nat. deorum, quid non sint quam quid sint, our subtle Schoolmen,' Cardans, Scaligers, profound Thomists, Frascatoriana \& Ferneliana acies, are weak, dry, obscure, defective in these mysteries, ... In former times, as we read Acts 23., the Sadducees denied that there were any such Spirits,

\footnotetext{
${ }^{7}$ Edgar Zilsel, "Copernicus and Mechanics," Journal of the History of Ideas, I ( 1940 ), I $13-118$.

${ }^{8}$ Leonardo Olschki, "Galileo's Philosophy of Science," The Philosophical Review, LII ( 1943 ), 352.

"Karl Mannheim, "On the Interpretation of Weltanschauung," in Essays on the Sociology of Knowledge, trans. Paul Kecskemeti (New York, r952), p. 66.
} 
Devils, or Angels. So did Galen the Physician, the Peripateticks, even Aristotle himself, as Pomponatius stoutly maintains, and Scaliger in some sort grants; though Dandinus the Jesuit, com. in lib. 2. de animâa, stiffly denies it. Sustentiae separatae, and intelligences, are the same which Christians call Angels, and Platonists Devils, for they name all the Spirits daemones, be they good or bad Angels, as Julius Pollux, Onomasticon lib. I. cap. I, observes. Epicures and Atheists are of the same mind in general, because they never saw them. Plato, Plotinus, Porphyrius, Iamblicus, Proclus, insisting in the steps of Trismegistus, Pythagoras and Socrates, make no doubt of it: nor Stoicks, but that there are such spirits, though much erring from the truth (I, 205-6).

The interesting thing about the passage, indeed the whole book, is that the emphasis lies not in the logic but on the quantitative accumulation of authorities. The same sort of accumulation occurs in the more important medical parts of the Anatomy. Dispensing rapidly with the stars as the remotest cause of melancholy, Burton proceeds to the physiological causes of melancholy in phlegmatic persons. "Valescus," he writes "assigns their strong imagination for a cause, Bodine abundance of wind, Gordonius of seed, and spirits, or atomi in the seed, which cause their violent and furious passions. Sanguine thence are soon caught, young folks most apt to love, and by their good wills, saith Lucian, would have a bout with every one they see: the colt's evil is common to all complexions." He then goes on to describe the case of Lucian's Theomnestus, who apparently suffered a severe and chronic case of satyriasis. Still another in Anacreon confessed that "he had twenty sweet-hearts in Athens at once, fifteen at Corinth, as many at $T$ hebes, at Lesbos, and at Rhodes, twice as many in Ionia, thrice in Caria, twenty thousand in all. . ." And the cause?

Guianerius, tract. 15. cap. 14, refers all this to the hot temperature of the testicles; Ferandus, a Frenchman, in his Erotique Mel. . . . to certain atomi in the seed, such as are very spermatick and full of seed. I find the same in Aristot. sect. 4. prob. 17. si non secernatur semen, cessare tentigines non possunt, as Guastavinius, his Commentator, translates it, for which cause these young men that be a strong set, of able bodies, are so subject to it. Hercules de Saxonia hath the same words in effect (III, 66, 67).

Here again is the same quantitative if repetitive accumulation of authorities. There are about one thousand authorities mentioned in the Anatomy. What is being demonstrated here by Burton is the 
quantifying tendency of the newly developing science. Burton's procedure reveals the development of the quantifying style of thought, without his necessarily being aware of what he was doing. His Anatomy is a good illustration of the unevenness of the development of the new Weltbild. That this procedure is not unique in Burton can be seen in the work of Bruno. Speaking of Bruno's style, Olschki remarks that Bruno's most frequently used device is Enumeratio. On almost every page of Bruno's Italian dialogues Bruno ranges words and phrases in layers, the intent of which is to convince by exhausting the subject in every direction and to compel belief by the quantity of evidence. Although Bruno consciously rejected a quantitative interpretation of nature, he is fascinated with number. When, for example, he presents an argument between two people, he mentions all those circumstances in numerology, philosophy, the animal kingdom, in history and legend, where the appearances of two (Zweiheitsercheinungen) occur. ${ }^{10}$ Burton's style never reaches this level of superconsistency, but it is in the same direction:

Give me but a little leave [writes Burton on Religious Melancholy], and I will set before your eyes in brief a stupend, vast, infinite Ocean of incredible madness and folly: a Sea full of shelves and rocks, sands, gulfs, Euripuses, and contrary tides, full of fearful monsters, uncouth shapes, roaring waves, tempests, and Siren calms, Halcyonian Seas, unspeakable misery, such Comedies and Tragedies, such absurd and ridiculous, feral and lamentable fits, that I know not whether they are more to be pitied or derided, or may be believed, but that we daily see the same still practiced in our days, fresh examples, nova novitia, fresh objects of misery and madness in this kind, that are still represented unto us, abroad, at home, in the midst of us, in our bosoms (III, 359-60).

This is a species of rhetoric which achieves its effect not, to be sure, by a Johnsonian balance, but by a special kind of Enumeratio, by sheer copiousness of illustrations and proofs, many of which are protracted repetitions. J. Max Patrick has shown that between the first and sixth editions of the Anatomy Burton added not new lines of thought but interpolated qualifications, expanded lists, further references, and newly discovered authorities. ${ }^{11}$ This type of addition shows that Burton's habit of thought tended toward quantification, and this characteristic links him to the newly developing science.

${ }^{10}$ Galilei und seine Zeit (Halle [Saale], I 927), pp. 54-55.

11 "Robert Burton's Utopia," PQ, XXVII (1 948), 348. 
Burton is connected with the developing scientific attitude in other ways. His analysis of England's economic and social condition, ${ }^{12}$ contained largely in his Preface, is similar to that of contemporary social theorists, although he never achieves their level of analysis.

We have seen that the new way of life produced a tendency to analyse abstractly and empirically. Although this method of analysis is most clearly seen in physics and astronomy, it becomes visible by the early 16 th and $17^{\text {th }}$ centuries in the analysis of economic, political, and legal problems. ${ }^{13}$ By the 16 th century the normative approach of the Scholastics gave way in the work of Machiavelli, Grotius, Mun, and others, to a thoroughly secular analysis of society. In these writers society is regarded as a self-regulating economic or political machine whose governing laws can be uncovered by rational analysis, and which, in turn, can be manipulated by the judicious application of rationally-arrived at policies. The theoretical assumptions of these writers find their counterparts in Galileo: just as Galileo assumed that matter was everywhere the same, so Machiavelli assumed as axiomatic that human nature was always and everywhere the same. ${ }^{14}$ Similarly, by assuming that all individuals will behave rationally and with enlightened self interest in the pursuit of profit, the economic theoreticians were conceiving of an abstract homo economicus who is part of a rationally understandable economic machine. With the constituents of the economic whole thus abstracted and homogenized, it was possible to formulate economic laws in a thoroughly Galilean manner; that is, we can arrive at an abstraction that governs and explains particular phenomena, e.g., Gresham's law, or discover causal relations between bullion, trade, and prices; prices and quantity of industrial output; or manufactured output and "treasure."

Although Burton was a divine and there is much theology in the Anatomy, his investigation of the economic condition of England is nevertheless clearly in line with the secularizing tendency of the new thought. His discussion of industry and trade is just as theoretical as that of Thomas Mun, for example, and just as mercan-

${ }^{12}$ See William R. Mueller, The Anatomy of Burton's England (Berkeley, r952).

${ }^{13}$ For the direction of the following analysis, see Ernst Cassirer, The Myth of the State (New York, 1955), Chaps. XI and XII; Harold Laski, The Rise of European Liberalism (London, I947), Chaps. I and II.

${ }^{14}$ Olschki, Machiavelli the Scientist (Berkeley, 1945), p. 3 r. 
tilist. He begins with no a priori assumptions, such as religious or ethical norms, which had been the procedure of medieval writers on economic problems. Like Mun, Burton wished to find the real basis for wealth, and by a method of comparative analysis that ranges horizontally and vertically in history, he accumulates evidence in his usual manner to show that it is industriousness coupled with indigenous production and trade that produces wealth. For, he argues, there have been and there still are states, such as Holland, that are devoid of natural resources but which are prosperous by virtue of industry and trade energetically pursued. Burton's method, not unlike that of Galileo and Machiavelli, ${ }^{15}$ is to isolate a problem and by accumulation of empirical evidence pursue his problem to a solution. As in Machiavelli the learned quotations do not enrich or reinterpret some a priori principle. However incongruously employed, the empirical evidence piles up in the form of Enumeratio to illustrate a theoretical point. And in his anxiety to prove that small, barren principalities, such as he conceives England to be, can be wealthy, he asserts that "The lesser the territory is, commonly the richer it is" (I, IOO). The logic is faulty, the citations from Antiquity are irrelevant, but the Galilean method of generalizing is clear enough. The result is a statement that has the force of law: a country can be wealthy only if it has a flourishing and growing home industry and trade. As in Galileo, the experimental data are paradoxically irrelevant to the operation of the law, ${ }^{16}$ so in Burton the evidence can be drawn from anywhere and from any time in history, to illustrate the generalization that tends to have the quality of law.

Burton's method of isolating a practical problem and dealing with it empirically is Galilean, and this procedure characterizes not only his Preface, but indeed his whole book. In the Preface Burton poses the practical question, what are the causes, symptoms, and cures for melancholy, a disease which we see all around us and which can affect both individuals and kingdoms? He then formulates an hypothesis to the effect that melancholy is an organic part of the universe: "Kingdoms and Provinces are melancholy, cities and families, all creatures, vegetal, sensible, and rational, that all sorts, sects, ages,

\footnotetext{
${ }^{15}$ Leonardo Olschki, Bildung und Wissenschaft im Zeitalter der Renaissance (Leipzig, 1922), pp. 305-306. See also the same author's Machiavelli the Scientist, pp. 25-26.

${ }^{16}$ Lewin, p. I 2.
} 
conditions, are out of tune" $(\mathrm{I}, 39)$. And it is to deal with this central problem, the causes and cure of melancholy, that the vast accumulation of authorities treated like empirical evidence follows.

That Burton regards vegetal creatures liable to melancholy is perhaps an example of the quaintness of his mind or its unscientific character. Yet, it is possible to regard this seeing of melancholy in every corner of the universe as Galilean. In Galilean thought the physical world is conceptualized as a comprehensive all-embracing unity in which matter is unalterably the same throughout. The courses of the stars, the falling of bodies-all are governed by the same law and consist of the same matter. This "homogenization of the physical world," to use Lewin's phrase (p. Io), appears in Burton in the assertion that vegetal beings can be melancholy, for if matter is everywhere the same and if it is governed by the same laws, then any one part of the universe will behave like any other part. The important point here is not that in this case the method leads to error, but that the method is scientific and consistent. However unconsciously the method is being employed, Burton, like Galileo, is seeking out the laws which govern nature.

The entire structure of the argument on the causes of melancholy rests on the laws of cause and effect in a mechanistically conceived physiology: given a particular imbalance of the four humors, which are thought of as bodily fluids, it inevitably follows that melancholy of one sort or another will occur. Burton, however, is undecided "whether (melancholy) be a cause or an effect, a disease or symptom" (I, I93). In any event, his attitude is to see material operating causally. Nor is he certain about which part of the body is primarily affected: the heart, the brain, or what; but certain it is that the brain as a "similar" part must be affected as are other parts:

They do compati, and have a fellow-feeling [Italics mine-LG], by the law of nature: but forasmuch as this malady is caused by precedent imagination, with the appetite, to whom spirits obey, and are subject to those principal parts, the brain must needs primarily be misaffected, as the seat of reason; and then the heart, as the seat of affection.... For our body is like a clock; if one wheel be amiss, all the rest are disordered, the whole fabrick suffers (I, 195).

The whole attitude here is a mixture of Galileanism and Aristotelianism: the interrelation of the parts of the whole is conceived mechanistically (as the comparison to the clock shows), causally, and 
lawfully; yet, parts affect other parts out of "fellow-feeling," which is a valuative way of regarding the process. All the contradictions notwithstanding, the determinism of Burton's physiology is apparent: it is a conception in which a pathological imbalance of the humors produces pathological behavior.

But this confusion of methods does not exhaust the contradictory character of his work. On the one hand, he closely examines the Copernican hypothesis and on rational grounds doubts its validity; ${ }^{17}$ on the other, he castigates the deists and philosophers for demanding sensible proofs in religious matters (III, 440). But his tilt with the atheists only lands him on the road to the secularization of science. He quotes Scaliger to the effect that "Nature signifies God's ordinary power," and Calvin to the effect that "Nature is God's order," concluding that "God is all in all, God is everywhere, in every place" (III, 44I). But the argument that God is in nature or works through nature does not denigrate the conception that nature is lawful. Entangled, he regards the theological problems raised by the new astronomy as "absurd and brainsick questions, intricacies, froth of human wit, and excrements of curiosity, \&c. which, as our Saviour told his inquisitive Disciples, are not fit for them to know" (II, 69). He finally declares that God in his good time will reveal these mysteries to some few at least, and he turns with immense relief to continue his empirical investigation of the air (II, 69). In a typical empiricist manner he leaves the question of what is knowable and how it is known to continue to accumulate data. Contradictions such as these must be regarded as inevitable in a mind which is only gradually and unevenly changing from the Aristotelian to the Galilean point of view. The effect of the collision of these two distinct styles of thought is a literary style that speeds blindly as the quantitative side seeks expression, only to pull up short when its direction and goal are not clearly understood. The inconsistencies in thought are reflected in the peculiarities of style.

The amount of Latin in the book has often been remarked upon, but that a book on science should have been written in English, while not unheard of, is noteworthy. Burton declares that "it was not mine intent to prostitute my muse in English, or to divulge secreta Min-

${ }^{17}$ Robert M. Browne, "Robert Burton and the New Cosmology," MLQ, XIII (1952), I $35,138-39$. 
ervae, but to have exposed this more contract in Latin, if I could get it printed." But the printers would have nothing in Latin (I, 28-29). Having said so much by way of apology and explanation for not writing in Latin, he plunges into a vigorous defense of the plain vernacular style. First he defends his citations of authorities, and then he proceeds to characterize his own style:

And for those other faults of barbarism, Dorick dialect, extemporanean style, tautologies, apish imitation, a rhapsody of rags gathered together from several dung-hills, excrements of authors, toys and fopperies confusedly tumbled out, without art, invention, judgement, wit, learning, harsh, raw, rude, phantastical, absurd, insolent, indiscreet, ill-composed, indigested, vain, scurrile, idle, dull and dry, I confess all ('tis partly affected) thou canst not think worse of me then I do of myself (I, 24).

This is playful half-truth and mock modesty; but in a more serious vein he says that his style is extemporaneous, composed "without all affectation of big words, fustian phrases, jingling terms, tropes, strong lines, that like Acestes' arrows caught fire as they flew, strains of wit, brave heats, elogies, hyperbolical exornations, elegancies \&c." Most important of all, he says that he "respects matter, not words." "I neglect phrases," he asserts, "and labour wholly to inform my reader's understanding not to please his ear; 'tis not my study or intent to compose neatly, which an Orator requires, but to express myself readily \& plainly as it happens" ( $\mathrm{I}, 3 \mathrm{O}-3 \mathrm{I}$ ). The point at issue here is the choice between a rhetorical style or plain English for scientific purposes. In advocating the latter, Burton was groping in the direction of a style suitable for scientific discourse. To be sure he never achieved it, but neither did Bacon in his scientific work. At best he arrived at a half-way house, the Anti-Ciceronian style. ${ }^{18} \mathrm{Be}$ cause his scientific method is only partially developed, Burton's style never achieves the economy, precision, and clarity of men like Hobbes or Glanvill.

Let us now return to Burton's use of citations. Since the new scientific method had "no authority, support, or confirmation, other than the logical necessity of its mathematical demonstrations and the concrete evidence of its experimental tests, ${ }^{19}$ citations of ancient

18 On the Anti-Ciceronian and scientific styles, see Richard F. Jones, "Science and English Prose Style in the Third Quarter of the Seventeenth Century," PMLA, XLV (1930), I $004-6$.

${ }^{19}$ Olschki, "Galileo's Philosophy of Science," p. 357. 
authorities became superfluous and their use increasingly under attack. As a Humanist Burton feels constrained to defend his citations. He becomes pettish when he asserts that he "must and will" use citations. His defense is not very convincing. We have already seen that Burton's copiousness is an expression of the quantitative style of thought, the accumulation through Enumeratio of pragmatic arguments to support a central thesis. But this does not explain the fact of citation. Stylistically Burton's method of citing authorities stands between that of the typical Humanist, among whose ranks he enlists himself, and a social scientist like Machiavelli. In the former, the citations are in the tradition of Eloquentia, a rhetorical device in which words and phrases from classical authors are cited for the rhythmical contrast they afford. The result is that frequently a work has the character of a mosaic in which the originality of the thought is buried. In the latter, the citations are so intimately interwoven into his argument that it is almost impossible to distinguish what is the classical thought and what Machiavelli's. Like his contemporaries whose concern was the practical, Machiavelli employs what is useful wherever he finds it. Merely as a concession to the taste of his times does he quote a word or two from The Aeneid or a couple of lines from Juvenal. ${ }^{20}$ Burton's style results from the uncritical combining of the Humanistic Eloquentia and the scientific attitude. But Burton's Eloquentia is not the same thing as the Humanists': it is partly the embellishment of a text with classical citations, but it is more Emmeratio, which, we have shown, is the manner in which Burton unconsciously and compulsively expresses the quantitative side of science. The two rhetorical devices become the means of expressing quantity.

The Eloquentia-Enumeratio combination produces a work that has all the appearance of a mosaic, a "Cento out of divers Writers," and what is Burton's tends to recede behind the façade of authorities. Burton's originality consists in gaining some insight by a blindly applied method. In a great number of places the contradictory citations lead Burton into an impasse. In his "Digression on Air" Burton piles up all the evidence with regard to the cosmologies then offered to explain the new astronomical observations and refuses to endorse any of them on purely rational grounds. This characteristic inde-

${ }^{20}$ Olschki, Bildung und Wissenschaft, pp. 3 I I-I 2. 
cision is not merely a stylistic quirk; it may be seen as the scientific desire for objectivity in a mind not fully conscious of its method of analysis. His pragmatism all too often leads to no evaluation; hence, to pure enumeration. Yet, this objectivity and pragmatism are parts of the "new philosophy."

Since the manifestations of the scientific method in Burton are based on intuition and are devoid of the inner compulsion towards coherence and conceptual precision, the subjective side of his personality emerges in the form of humor, pride, salaciousness, playfulness, or capriciously irrelevant digressions. The subjective, which is perhaps the intrusion of individuality that arose as a new cultural phenomenon in the Renaissance, and the objective, the new scientific method, appear alternatively or together as a "confused lump," giving Burton's Anatomy its peculiar style. The style is a product neither solely of an emerging $W$ eltbild nor solely of emerging individuality. It is a product of an emerging modern society. 